\title{
Wind Turbine design and fabrication to power street lights
}

\author{
Mohammad Khan , Mohammed Alavi, Nithin Mohan, AbidAzeez, Abdul Shanif and Bilal Javed \\ College of Engineering, Abu Dhabi University, Abu Dhabi, UAE
}

\begin{abstract}
The objective of this work was to design and build a wind turbine which can be used to power small street lights. Considering the typical wind speeds in Abu Dhabi, UAE and ease of construction, the design of the wind turbine was chosen to be Sea Hawk design from vertical axis wind turbine category. A three phase AC generator was used for its availability over the DC motors within the region. A $12 \mathrm{~V}$ battery was used for storage and a charge controller was used for controlling the charge flow into the battery and for controlling the turbine rotation when the battery is fully charged. The blades used in the turbine were made of foam board according to the NACA 0018 airfoil shape with a chord length of $15 \mathrm{~cm}$. The connecting shaft was made of stainless steel. Structural analysis and CFD analysis were performed along with other calculations. Testing was executed to calculate the voltage output from the turbine at different wind speeds. The maximum voltage the turbine produced at $6.4 \mathrm{~m} / \mathrm{s}$ wind speed was 2.4 Vand the rotational speed of the turbine was $60.3 \mathrm{rpm}$.
\end{abstract}

\section{Introduction}

Wind turbines typically are divided into two types based on their axis of rotation with respect to the wind flow direction; Horizontal Axis Wind Turbine (HAWT) and Vertical Axis Wind Turbine (VAWT). HAWT has blades that are similar to propellers that spin on horizontal axis. The position of main rotor shaft and electrical generators in horizontal axis turbine is at the top of a tower provided that this must be pointed in the direction of wind. Typically, the gearbox combined with the high-speed shaft increases the rotation of about 30-60 rpm to almost $1200-1500 \mathrm{rpm}$. This is the typical rotation speed required for generators used in HAWT [1]. The offshore wind turbines have the advantage in case of noise pollution as it is far from shore without affecting the people and are less affected by turbulence whereas the onshore turbines create noise pollution and are affected more by turbulence [2]. In a VAWT, the main rotor shaft is fixed vertically. Vertical axis wind turbines can be subdivided into two kinds: Darrieus and Savonius [1]. Typical Darrieus wind turbine (different types shown in Fig. 1) contains 2 or 3 blades [3].
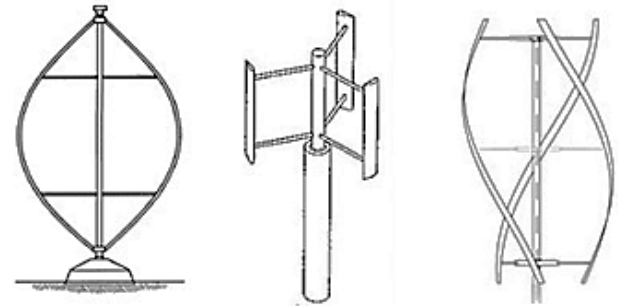

Rotor Darrieus

Rotor Darrieus H
Savonius drag-based VAWT works similar to the paddle propelling in a boat. The drag is the pressure or thrust developed when wind passes through the blade. The blade is $S$ shaped cross section; this is to implement the drag technique and also to provide certain lift [4].UAE is currently in the process of determining the viability in wind farm projects within the country. UAE Ministry of Energy is carrying out various research projects for further understanding the variability of wind from year to year [6].

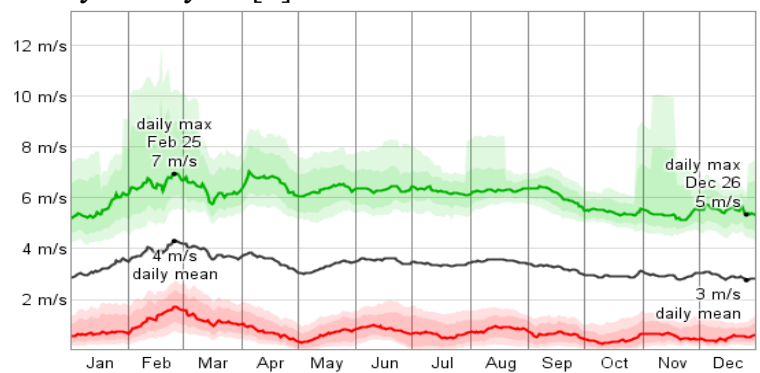

Figure2. Red is average daily minimum, Green is maximum, and black is average wind speed with percentile bands [7].

Figure 2 shows the wind speed data over a year in Abu Dhabi. Daily maximum wind speed ranges from lowest $5 \mathrm{~m} / \mathrm{s}$ to highest $7 \mathrm{~m} / \mathrm{s}$. The lowest daily wind speed can go to a maximum of $2 \mathrm{~m} / \mathrm{s}$. In an average curve, the maximum wind speed is found to be $5 \mathrm{~m} / \mathrm{s}$ and minimum is $3 \mathrm{~m} / \mathrm{s}$. Hence the design constraint was selected to be a wind speed of around $5 \mathrm{~m} / \mathrm{s}$ [7]. The average wind speed in Abu Dhabi is less than $5 \mathrm{~m} / \mathrm{s}$ and VAWT can be utilized at such wind speeds. The start-up wind speed generally is $2 \mathrm{~m} / \mathrm{s}$ for the same. Sea hawk design as shown

Figure 1. Types of Darrieus VAWT [3] 
in Fig. 3 satisfies the regional conditions and is appropriate for Abu Dhabi weather conditions [5].

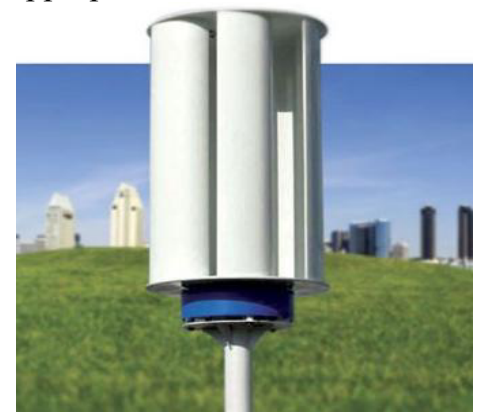

Figure3. Sea Hawk turbine [5].

The objective of the present work is to design and construct a wind turbine to power small street lights of typically $30 \mathrm{~W}$ lamps. The wind turbine is to be designed for wind conditions encountered in Abu Dhabi UAE. The turbine should run effectively with an average wind speed of $5-6 \mathrm{~m} / \mathrm{s}$. A battery will be used to store energy while the wind turbine is running during the day. The same can power the street light after sunset. In addition, the whole turbine should be modular and easily manufactured with inexpensive material requirements. Considering the use for street lighting, the typical wind velocities available in Abu Dhabi, and the ease of manufacturing Sea Hawk VAWT was selected as a good candidate to serve the purpose.

\section{Design of the Wind Turbine}

Swept area of the wind turbine is the area of the wind turbine which captures the wind. The power available from the wind turbine increases with an increase in the swept area. Another parameter that greatly affects the power available from the wind turbine is the wind speed [8]. Kinetic energy can be calculated as:

$\mathrm{KE}=0.5 \mathrm{mV}_{\infty}{ }^{2}$; where $V_{\infty}$ is the free stream velocity and $m$ is the mass of air trans versing such that $m=\rho A V_{\infty}$ in which $\mathrm{A}=$ swept area and $\rho=$ density of air

Therefore,

$$
\mathrm{KE}=0.5 \rho \mathrm{AV}_{\infty}{ }^{3}
$$

Including coefficient of performance in equation (1), the power output can be determined as:

$$
\mathrm{P}_{\mathrm{w}}=\frac{1}{2} \mathrm{C}_{\mathrm{p}} \rho A \mathrm{~V}_{\infty}^{3}
$$

Power density is the terminology used to define the available power per unit area swept by the blade/airfoil [9]. Power density can be calculated as:

$$
\mathrm{p}=\frac{1}{2} \mathrm{C}_{\mathrm{p}} \rho \mathrm{V}_{\infty}{ }^{3}
$$

Symmetrical shape is easier to manufacture than curved shapes. NACA 0018, 0012, 0015 are all symmetric in shape. NACA four series is recommended since symmetrical airfoils work better for higher Reynolds number; particularly NACA 0012, 0015, 0018. These are more appropriate for smaller angle of attack [8].

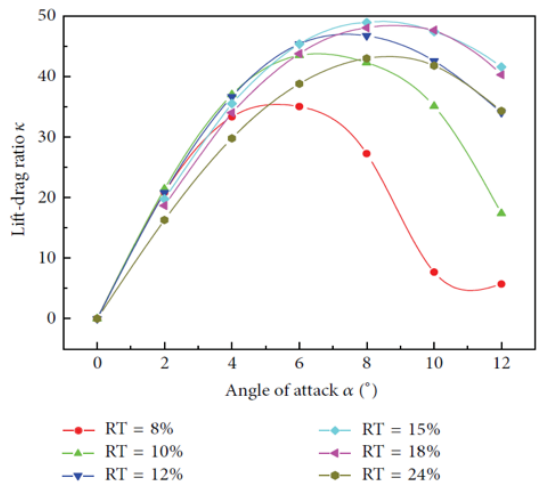

Figure 4. Lift-drag ratio of symmetric airfoils at various relative thickness [9].

Figure 4represents comparison between six different NACA airfoil thicknesses which include $8,10,12,15,18$, and 24 percentages. The relative thickness 'RT' represents thickness / chord ratio $(\mathrm{t} / \mathrm{c}$ ratio) and is the maximum thickness of the airfoil expressed as a percentage of the chord.Considering symmetric airfoil shapes, the airfoils with $15 \%$ thickness has the highest lift drag ratio. This means $15 \%$ thickness can provide the maximum lift and least drag. The second highest lift drag ratio is for $18 \%$ thickness NACA airfoil. It is evident in the graph that when angle of attack increases after a specific value, the drag element increases and the ratio decreases. When thickness increases beyond a limit, the drag also increases accordingly. Thus airfoil with thickness $15 \%$ or $18 \%$ is preferred. It should also be considered that $18 \%$ is thicker than $15 \%$ and is more robust than $15 \%$. Another important finding is that thicker airfoil increases the startup torque. It was found that $19 \%$ thickness showed good start-up and traverse characteristics. Theoretically it is proven that $18 \%$ has better performance at low Reynolds number and highest power coefficient was achieved at $18 \%$ [9]. Studies [8] prove that a larger leading edge radius is preferred to be less sensitive to roughness. Thick blunt trailing edge is preferred for increasing lift [9]. Choosing an appropriate number of blades for the turbine is a balance between blade stiffness and aerodynamic efficiency. Increasing the blade number for a specific radius and thickness leads to sacrificing blades stiffness for a very slight increase in aerodynamic efficiency. Single bladed turbines suffer from a parasitic drag. Two bladed rotors are more sensitive towards mass imbalance vibrations and causes higher operating cost and maintenance compared to three blades. Minimum three blades are required to decrease vibrations due to mass imbalance issues [9].In the sea hawk type of vertical axis wind turbines, the blades are not cambered and are symmetric. The diameter of the turbine is $0.80 \mathrm{~m}$ and $1.2 \mathrm{~m}$ tall. All the blades positions are distributed evenly. Blades can be made from light and inexpensive materials. Sea Hawk design was chosen as the prototype design. This decision was made after comparing the score in efficiency, cost, ease of manufacturing, and ease of maintenance. The blades in this type of turbine can be designed in straight, symmetric, and anti-symmetric airfoil shapes.

Initial optimized parameters have been chosen to set the initial design of the turbine. Table 1 summarizes the 
initial dimensions of the turbine which were obtained based on best dimensions of the airfoil.

Table 1. Starting parameters.

\begin{tabular}{lll}
\hline Symbol & Parameter & Value \\
\hline Vo & Wind speed & $5 \mathrm{~m} / \mathrm{s}$ \\
TSR & Tip speed ratio & 0.625 \\
$\mathbf{R}$ & Rotor Radius & $0.385 \mathrm{~m}$ \\
$\mathbf{C}$ & Blade Chord & $0.07 \mathrm{~m}$ \\
$\mathbf{L}$ & Blade length & $1.22 \mathrm{~m}$ \\
$\mathbf{N}$ & Blade numbers & $6,8,15,16$ \\
\hline
\end{tabular}

Once the initial dimensions and TSR are specified the next step is to find the solidity which is a dimensionless parameter which will help to find the geometry of the VAWT. The blade solidity ' $\sigma$ ' can be calculated as:

$\sigma=\frac{\mathrm{B} C}{\mathrm{R}}$

where ' $\mathrm{B}$ ' is the number of blades; ' $\mathrm{R}$ ' is the radius of the rotor; ' $\mathrm{C}$ ' is the chord length

An increase in solidity increases the production of the higher torque at the low tip speed ratios. Table 2 shows properties of different materials considered for the blade. The wind turbine structure is the main source of the stresses as well as the change of input forces [11].

Table 2. Material properties.

\begin{tabular}{|c|c|c|c|c|c|}
\hline Material & $\begin{array}{l}\text { Stiff } \\
\text { ness } \\
\text { (GP } \\
\text { a) } \\
\end{array}$ & $\begin{array}{l}\text { Tensile } \\
\text { Streng } \\
\text { th } \\
\text { (MPa) }\end{array}$ & $\begin{array}{l}\text { Density } \\
\left(\mathrm{g} / \mathrm{cm}^{3}\right)\end{array}$ & $\begin{array}{l}\text { Elonga } \\
\text { tion at } \\
\text { break } \\
(\%)\end{array}$ & $\begin{array}{l}\text { Max } \\
\text { temp } \\
\left({ }^{\circ} \mathrm{C}\right)\end{array}$ \\
\hline Steel & 30 & 190 & 7.5 & 15 & 550 \\
\hline $\begin{array}{l}\text { Alumi } \\
\text { num }\end{array}$ & 10 & 90 & 2.7 & 12 & 400 \\
\hline $\begin{array}{l}\text { Glass- } \\
\text { E }\end{array}$ & 73 & 3500 & 2.54 & 3 & 350 \\
\hline $\begin{array}{l}\text { Carbo } \\
\text { n }\end{array}$ & 350 & 4000 & 1.75 & 1.8 & 500 \\
\hline $\begin{array}{l}\text { Arami } \\
\text { d }\end{array}$ & 120 & 3600 & 1.45 & 11 & 250 \\
\hline $\begin{array}{l}\text { Foam } \\
\text { T90 }\end{array}$ & 0.5 & 1.5 & 0.065 & 0.2 & 70 \\
\hline
\end{tabular}

The shaft of the turbine $(1.05 \mathrm{~m}$ long) is made up of stainless steel for its advantages such as durability and resistance to corrosion and rust. At some point the flow of charge from the generator to the battery should be regulated. According to the generator rated power output of $30 \mathrm{~W}$ and voltage of $12 \mathrm{~V}$ FW03-12A waterproof charge controller was chosen. The specifications of the controller are mentioned in Table 3.

Table 3. Controller specifications.

Specifications

\begin{tabular}{ll}
\hline Rated power & $300 \mathrm{~W}$ \\
Battery Voltage & $12 \mathrm{~V}$ \\
Brake voltage & $13.5 \mathrm{~V}$ \\
Level of protection & IP67 \\
\hline
\end{tabular}

\section{Design Parameters}

The main design objective of the turbine is to produce an output power of $30 \mathrm{~W}$ or above to power LED street lights. The design constraints of the turbine are the turbine diameter, airfoil type, chord length, number of blades, and pitch angle. The input parameters of the design are the rotor radius, blade length, blade chord length, and number of blades. The input parameters of the wind are the free stream wind speed, and air density. The parameters such as swept area, power available from the wind, angular velocity, rated blade velocity, tip speed ratio, lift force, drag force, tangential force, normal force, torque and expected power output is calculated.

Using the equation for Swept Area,

Swept Area $(A)=H \times D$

Using equation (2),

$$
A=0.832 m^{2}
$$

Power available from wind $\left(\mathrm{P}_{\mathrm{w}}\right)=63.7 \mathrm{~W}$

From the literature review and based on the wind data, the cut in speed $\left(\mathrm{V}_{\mathrm{d}}\right)$ was assumed to be $3.13 \frac{\mathrm{m}}{\mathrm{s}}$

To find the Angular velocity $(\omega)$,

$$
\omega=\frac{\mathrm{V}_{\mathrm{d}}}{\mathrm{R}}=7.825 \frac{\mathrm{rad}}{\mathrm{sec}}(6)
$$

Using the equation for Blade velocity,

Blade velocity $\left(V_{b}\right)=R \times \omega=3.13 \frac{\mathrm{m}}{\mathrm{s}}$

Using equation, the magnitude of relative velocity is

$$
|\vec{W}|=V_{\infty} \sqrt{\left(\frac{\omega R}{V_{\infty}}+\cos \theta\right)^{2}+(\sin \theta)^{2}}(8)
$$

Finding the relative velocity, lift force, drag force, tangential force, torque, expected power output and coefficient of performance when the blade position is at 30 degrees and the pitch angle is at 10 degrees. Fig. 5 shows the velocity vector when the blade is at positioned at 30 degrees.

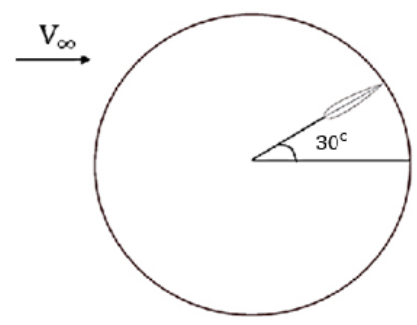

Figure 5. Velocity vector when blade is positioned at 30 Degree When the blade is in position which is the azimuth angle $(\theta)$ is at an angle of $30^{\circ},|\vec{W}|=6.29 \frac{\mathrm{m}}{\mathrm{s}}$

The angle of relative velocity can be found using equation,

$$
\varphi=\tan ^{-1}\left(\frac{\sin \theta}{\frac{\omega \mathrm{R}}{\mathrm{V}_{\mathrm{d}}}+\cos \theta}\right)-\frac{\omega \mathrm{x}_{0} \mathrm{C}}{\mathrm{W}}-\frac{\omega \mathrm{C}}{4 \mathrm{~W}}
$$

Where $\mathrm{x}_{0}$ is the blade attachment at the middle of chord length, thus $\mathrm{x}_{0}=0$. Therefore, $\varphi=12.36^{\circ}$

Using the equation for tip speed ratio,

$$
\lambda=\frac{\mathrm{R} \omega}{\mathrm{V}_{\infty}}=0.624(10)
$$

Angle of attack and pitching angle is related to each other and this can be mathematically modeled. By fixing the azimuth angle as $30^{\circ}$ and varying the pitch angle $-10^{\circ}$ to $60^{\circ}$ Fig. 6 was generated. 


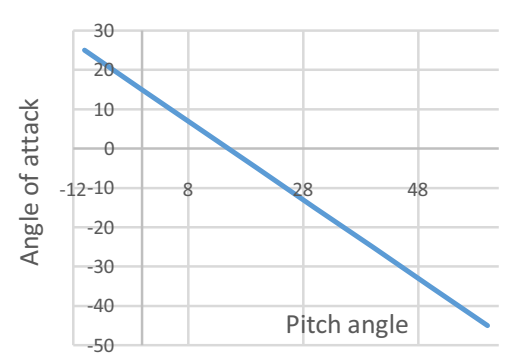

Figure 6. Angle of attack vs Pitch angle.

For the calculation, the pitch angle was assumed to be $10^{\circ}$. From the graph plotted in Fig. 6, the angle attack was found to be $5.025^{\circ}$.

RPM of the turbine

$N=7.825 \times \frac{60}{2 \pi}=74.72 \mathrm{RPM}$

Using equation for Reynolds number,

$$
\operatorname{Re}=\frac{\rho \mathrm{WC}}{\mu}=58284.79
$$

The values for $C_{L}$ and $C_{D}$ are found to be 0.7352 and 0.03446 from the table for NACA 0018. Using the angle of attack $(\alpha)$ which is equal to $5.025^{\circ}$.

Using the equation for lift force,

$$
\text { Lift Force }\left(\mathrm{F}_{\mathrm{L}}\right)=\frac{1}{2} \times \mathrm{C}_{\mathrm{L}} \times \rho \times \mathrm{W}^{2} \times \mathrm{A}_{\mathrm{P}}=2.779 \mathrm{~N}
$$

Using the equation for Drag Force,

$$
\operatorname{Drag} \text { Force }\left(F_{D}\right)=\frac{1}{2} \times C_{D} \times \rho \times W^{2} \times A_{P}=0.13 N
$$

Using the equation for Tangential Force,

$$
\mathrm{F}_{\mathrm{T}}=\mathrm{F}_{\mathrm{L}} \sin \varphi-\mathrm{F}_{\mathrm{D}} \cos \varphi=0.64 \mathrm{~N}
$$

Chord length for the turbine blade was determined after comparing and analyzing existing VAWT turbine designs. It was found that most of the turbine blade chord length was somewhere between $\frac{1}{15}^{\text {th }}$ to $\frac{1}{10}^{\text {th }}$ of the turbine diameter. But based on the preliminary design and sketches performed it was found that the gap between the turbine blades was huge so the chord length was increased to $15 \mathrm{~cm}$ from $7 \mathrm{~cm}$. According to the chosen NACA0018 blade, the thickness should be $18 \%$ of the chord length. The thickness of the blade was computed using equation (16) to be,

$$
\mathrm{T}=\mathrm{C} \times 0.18=15 \times 0.18=3 \mathrm{~cm}
$$

The effect of coefficient of lift as well as coefficient of drag will affect the overall performance of the turbine. $\mathrm{C}_{\mathrm{L}}$ and $\mathrm{C}_{\mathrm{D}}$ are functions of $R e$ and the particular airfoil section. The values of coefficient of lift and drag for the prototype blade with $15 \mathrm{~cm}$ chord length was taken from the table for NACA 0018. Using the equation for the coefficient of performance,

$$
\begin{gathered}
\mathrm{C}_{\mathrm{p}}=\frac{\text { Expected power output }}{\text { Power available from the wind }}=\frac{\mathrm{P}}{\mathrm{P}_{\mathrm{w}}} \\
\mathrm{C}_{\mathrm{p}}=\frac{\mathrm{C}_{\mathrm{T}} \times \mathrm{C} \times \mathrm{W}^{2} \times \mathrm{B} \times \lambda}{\mathrm{D} \times \mathrm{V}_{\infty}^{2}} \\
\mathrm{C}_{\mathrm{T}}=\mathrm{C}_{\mathrm{L}} \sin \alpha-\mathrm{C}_{\mathrm{D}} \cos \alpha=0.03 \\
\mathrm{C}_{\mathrm{p}}=\frac{0.03 \times 0.15 \times 6.29^{2} \times 0.624}{0.8 \times 5^{2}} \times \mathrm{B}
\end{gathered}
$$

The graph shown in Fig. 7 was generated by fixing the wind speed, diameter of the turbine, tip speed ratio, and the only variation used was the blade number. This was performed in order to choose the best number of blades for the turbine. However, 16 blades were rejected as it had almost same value of $\mathrm{C}_{\mathrm{p}}$ as 15 blades and also to reduce the added weight on the turbine.

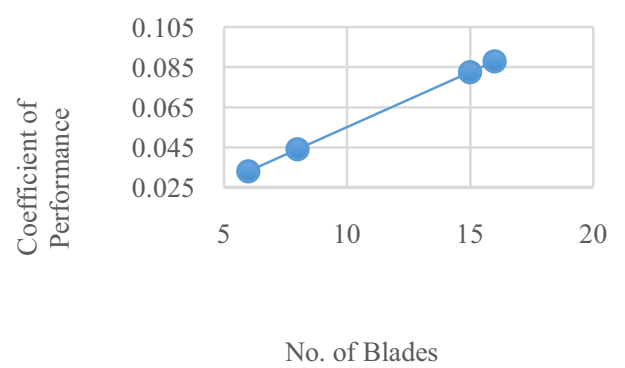

Figure 7. Graph of Coefficient of performance vs No. of blades. The torque of the turbine was found using the equation for torque

(18)

$$
\mathrm{Q}=\mathrm{B} \times \mathrm{F}_{\mathrm{T}} \times \mathrm{R}=15 \times 0.64 \times 0.4=3.84 \mathrm{Nm}
$$

Using the equation for the power output,

$\mathrm{P}=$ Torque $\times$ Angular Velocity $=\mathrm{Q} \times \omega=30 \mathrm{~W}$

Using the equation for power,

$$
\begin{gathered}
\mathrm{C}_{\mathrm{p}}=\frac{\text { Expected power output }}{\text { Power available from the wind }}=\frac{\mathrm{P}}{\mathrm{P}_{\mathrm{w}}} \\
\mathrm{C}_{\mathrm{p}}=0.474
\end{gathered}
$$

The above calculations for torque, expected power output, and power coefficient were calculated by assuming the blade position at 30 degrees from the reference and the pitch angle at 10 degrees.

\section{Structural Analysis of the Turbine}

Structural analysis of the turbine is one of the important parameters that need to be considered in terms of design. The factors considered in the structural analysis are maximum bending moment, normal and shear loads on the blades, allowable stresses, and moment of inertia on the blades.

The normal stress is calculated using equation

$$
\sigma_{\mathrm{N}}=
$$

Normal force

Area perpendicular to force

Normal force $\left(F_{N}\right)$ is calculated using equation

$\mathrm{F}_{\mathrm{N}}=\frac{1}{2} \times \rho \times \mathrm{C} \times \mathrm{L} \times \mathrm{W}^{2} \times \mathrm{C}_{\mathrm{N}}$

Where $C_{N}$ the coefficient of normal force, $\mathrm{C}$ is the chord length, $\rho$ is the density of air, and $\mathrm{W}$ is the relative velocity of the blade.

The coefficient of normal force is calculated to be

$$
\mathrm{C}_{\mathrm{N}}=\mathrm{C}_{\mathrm{L}} \sin \alpha+\mathrm{C}_{\mathrm{D}} \cos \alpha=0.09844
$$

Therefore, the normal force from (22) is $0.372 \mathrm{~N}$

The perpendicular area is found by assuming the blade as cuboid. Thus, the perpendicular area is found using equation

$$
\begin{gathered}
\mathrm{A}_{\mathrm{d}}=\text { thickness of blade } \times \text { length of blade } \\
\qquad A_{d}=0.0312 \mathrm{~m}^{2}
\end{gathered}
$$

Therefore, from $(21), \sigma_{\mathrm{N}}=11.923 \mathrm{~Pa}$

Shear stress occurs due to tangential force. The tangential force was found to be, $\mathrm{F}_{\mathrm{T}}=0.64 \mathrm{~N}$ which is same as the shear force $F_{S}$. The shear stress is calculated using equation (25) as 


$$
\tau=\frac{\mathrm{F}_{\mathrm{s}}}{\text { Blade area }}=4.1 \mathrm{~Pa}
$$

The bending moment is proportional to the centripetal acceleration. The centripetal acceleration is given by equation (26)

$$
\mathrm{a}_{\mathrm{n}}=\frac{v_{b}^{2}}{\mathrm{R}}=24.5 \mathrm{~m} / \mathrm{s}^{2}(26)
$$

Where, $a_{n}$ is the centripetal acceleration, $v_{b}$ is the blade velocity and $\mathrm{R}$ is the radius of the turbine.

Bending moment $=\mathrm{F}_{\mathrm{N}} \times$ Distance $=0.558 \mathrm{Nm}$

\section{Structural Design of the Rotor}

The material selection was done comparing stiffness, tensile strength, density, elongation at break, temperature up to which it can hold, cost and ease of manufacturing.

\begin{tabular}{llllll}
\multicolumn{7}{c}{ Table 4. Material } & Comparison [13]. & \\
\hline Material & $\begin{array}{l}\text { Stiff- } \\
\text { ness } \\
(\mathbf{G P a})\end{array}$ & $\begin{array}{l}\text { Tensile } \\
\text { Strength } \\
(\mathbf{M P a})\end{array}$ & $\begin{array}{l}\text { Density } \\
\left(\mathbf{g} / \mathbf{c m}^{\mathbf{3}}\right)\end{array}$ & $\begin{array}{l}\text { Elongation } \\
\text { at break } \\
(\mathbf{\%})\end{array}$ & $\begin{array}{l}\text { Max } \\
\text { temp } \\
\left({ }^{\circ} \mathbf{C}\right)\end{array}$ \\
\hline Steel & 30 & 190 & 7.5 & 15 & 550 \\
\hline Al & 10 & 90 & 2.7 & 12 & 400 \\
\hline Glass-E & 73 & 3500 & 2.54 & 3 & 350 \\
\hline Carbon & 350 & 4000 & 1.75 & 1.8 & 500 \\
\hline Aramid & 120 & 3600 & 1.45 & 11 & 250 \\
\hline FoamT90 & 0.5 & 1.5 & 0.24 & 0.2 & 70 \\
\hline
\end{tabular}

Foam board was selected as the material for the blades. Figure 8shows the schematic of NACA 0018 with $15 \mathrm{~cm}$ chord length.

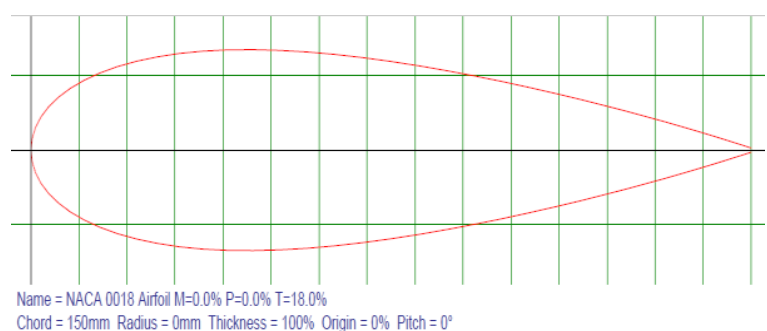

Figure 8. Schematic of NACA 0018 with $15 \mathrm{~cm}$ chord length

The mass of the manufactured blade was found to be $0.169 \mathrm{~kg}$.Acceleration analysis is done to determine theoretically that the turbine can achieve the desired RPM [14]. The inertial moments by approximating the blade shape as a cuboid; using Steiner theorem, is given using equation

$$
\begin{gathered}
\mathrm{I}_{\text {blade }}=\frac{1}{12} \mathrm{~m}_{\text {blade }}\left[\mathrm{C}^{2}+(0.21 \mathrm{C})^{2}\right]+\mathrm{m}_{\text {blade }} \mathrm{R}^{2} \\
\mathrm{I}_{\text {blade }}=0.273 \mathrm{kgm}^{2}
\end{gathered}
$$

Where $m_{\text {blade }}$ is the mass of the blade, $\mathrm{C}$ blade chord is, $\mathrm{R}$ is rotor radius. To get an approximate value of total momentum, inertial momentum is multiplied by the number of blades. The angular acceleration ( $\mathrm{rad} / \mathrm{s})$ can be calculated using equation

$$
A_{a}=\frac{Q}{I}(29)
$$

Where $\mathrm{Q}$ is the torque and $\mathrm{I}$ is the rotor inertial moment.

Relative velocity, torque, tangential, normal, lift, drag force, and expected power output were calculated for one blade positioned at $\theta=30^{\circ}$ and $\delta=10^{\circ}$. For VAWT the torque varies according to position of the blade and angle of attack, unlike HAWT were torque remains constant. Relative velocity, torque, tangential force, normal force, lift force, drag force, and expected power out depends on angle of attack. To achieve a constant torque and power output angle of attack has to be fixed.

Total moment of inertia

$$
\begin{aligned}
& =\text { moment of inertia of one blade } \\
& \times \text { number of blades }=0.405 \mathrm{kgm}^{2}
\end{aligned}
$$

Therefore, the angular acceleration is given by:

$$
\begin{gathered}
\mathrm{A}_{\mathrm{a}}=\frac{\mathrm{Q}}{\mathrm{I}}=\frac{3.84 \mathrm{Nm}}{0.405 \mathrm{kgm}^{2}} \times \frac{\mathrm{kg} \mathrm{m} / \mathrm{s}^{2} \times \mathrm{m}}{\mathrm{kg} \mathrm{m}^{2}} \\
=9.5 \frac{\mathrm{rad}}{\mathrm{s}^{2}}
\end{gathered}
$$

Load analysis for the blade dimensions can be divided into centrifugal and aerodynamic loads.

Centrifugal force is calculated by:

$$
F_{C}=m r \omega^{2}=4.1128 N
$$

The aerodynamic load is normal force $\left(F_{N}\right)$ and using equation (22) $F_{N}$ was found to be $0.372 \mathrm{~N}$.

The resultant force for one blade in rotation can be calculated. The assumption made for this is that both centrifugal and normal force are in the same direction.

$$
\begin{aligned}
& \qquad F_{R}=F_{C}+F_{N}=4 \\
& \text { Allowable stress }=\frac{\text { Yield Strength }}{\text { Tensile strength } \times \mathrm{FS}}
\end{aligned}
$$

Assuming factor of safety as 3 , the allowable strength of the Styrofoam board was found to be $0.5 \mathrm{MPa}$.

For $74.72 \mathrm{rpm}$, the angular velocity on the shaft can be calculated by:

$\omega=\frac{2 \pi N}{60}=\frac{2 \times \pi \times 74.72}{60}=7.8 \mathrm{rad} / \mathrm{s}(35)$

Torque on the shaft is based on the generator output power.

$$
\text { Torque }=\frac{\text { Power output from the generator }}{\omega}=3.8 \mathrm{Nm}(36)
$$

\section{Prototype and its testing}

A foundation is required to hold all the blades in place in a robust and straight manner. Two sheets $80 \mathrm{~cm}$ diameter and $2 \mathrm{~cm}$ thick was used on top and bottom made from Styrofoam sheets to satisfy these criteria. This adds strength to the shape and reduces the slanting of the blade while operating. The prototype has 15 blades with thickness of $3 \mathrm{~cm}$, height of $1 \mathrm{~m}$, and the material used was Styrofoam. The 3 phase AC PMA generator can produce 30 watt. It is $20 \mathrm{~cm}$ in diameter. The steel shaft was 1 meter long and with a diameter $1.2 \mathrm{~cm}$. The shaft goes through the Styrofoam sheets and covers almost all of the turbine height. The generator is fixed to the flange which is then fixed to the base. Flange acts as a mediator to the generator and base. The diameter of the flange is $9 \mathrm{~cm}$ and height is $25 \mathrm{~cm}$. Turbine base helps to avoid turbine from tipping due to the force from the wind. The base was made from marine plywood. The dimensions of base were $60 \mathrm{~cm}$ long, $54 \mathrm{~cm}$ wide and $14 \mathrm{~cm}$. The turbine is bolted to base to ensure stability.Table 5 shows the specification of the generator.

Table 5. Generator Specification

\begin{tabular}{ll}
\multicolumn{2}{c}{ Table 5. Generator Specification } \\
\hline Generator type & 3 phase AC PMG \\
\hline Rated voltage & DC 12V \\
Rated speed & $300 \mathrm{rpm}$ \\
Power output & $30 \mathrm{~W} \mathrm{@10} \mathrm{m/s}$ \\
Weight & $4.5 \mathrm{~kg}$ \\
\hline
\end{tabular}




\begin{tabular}{ll}
\hline Start-up wind speed & $2 \mathrm{~m} / \mathrm{s}$ \\
Torque & $9.74 \mathrm{Nm}$ \\
\hline
\end{tabular}

Figure 9shows a 3D isometric view of the turbine respectively. A 15 blade model shown below was developed using Solid works. This model was later used to perform structural analysis.

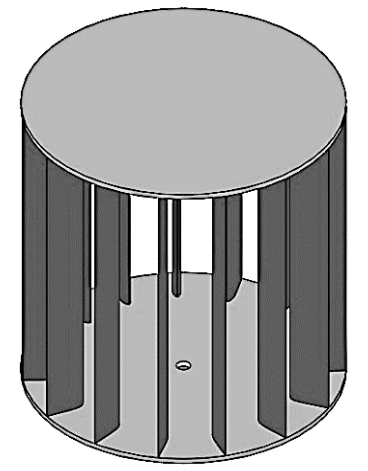

Figure 9. Engineering 3D isometric drawing of the turbine.

Wind turbine testing was done to ensure that it performs well at different wind speeds. Subjecting to various wind speeds the turbine voltage outputs were recorded and analyzed.Bending test was carried out in the lab using the method of three-point bending experiment. The strength and deformation capability of the blade was found out using this. Before performing the test, the blade was weighed and was found to be 0.169 kilogram The stress loaded on the blade was determined using the equation (37)

$\sigma_{\mathrm{b}}=\frac{3 \mathrm{~F}_{\text {Load ed }} \mathrm{S}}{2 \mathrm{CT}^{2}}$

(37)where

$\sigma_{\mathrm{b}}$ stands for the stress on the blade $F_{\text {Loaded }}$ is force loaded on blade, $\mathrm{S}$ means span, $\mathrm{b}$ is the width of the blade and $\mathrm{T}$ is the thickness of the blade. The blade broke at a load of $89.76 \mathrm{~N}$. Span was taken to $50 \mathrm{~cm}$ and ' $\mathrm{C}$ ' the chord length was $15 \mathrm{~cm}$ and thickness of the blade was $3 \mathrm{~cm}$. Therefore, the stress load came out to be $49.8 \mathrm{~Pa}$. The turbine was subjected to different wind speeds by the help of wind tunnel facility. Fig.10compares the different wind speeds and voltages as output while the turbine rotates.

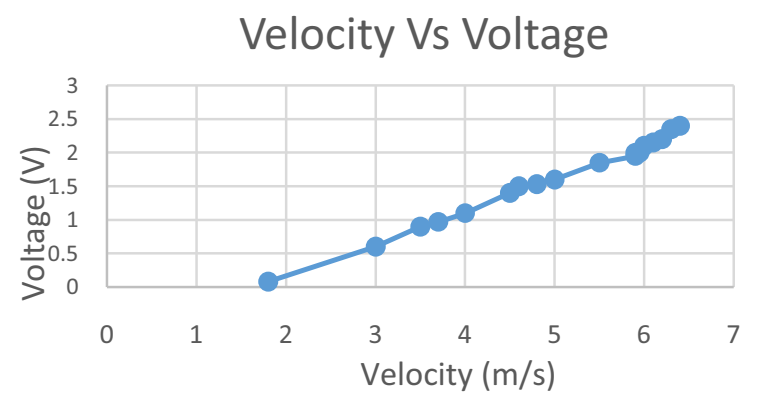

Figure10. Wind speed vs Voltage

As expected, when wind speed increases the voltage value increases. With the current facilities in wind tunnel the maximum voltage achieved was 2.4 volts with a wind speed of $6.4 \mathrm{~m} / \mathrm{s}$. The least voltage achieved was during $1.8 \mathrm{~m} / \mathrm{s}$ wind with a voltage value of 0.08 volts. RPM of the turbine was calculated using tachometer counter and was found to be 60.3 .

\section{Conclusion}

In conclusion, the project's initial intention was to design, create, and simulate a wind turbine which can be used to power LED street lights. The necessary approaches starting from literature review to find all the necessary background details required, collecting the wind data, selecting the appropriate turbine, blade type, determining the components required, calculating the power density, structural analysis, CFD analysis, building the prototype, till the testing of the turbine were performed. From the literature review it was found that VAWT works better due to the facts that the efficiency is better, works with lower wind speeds, cheaper, smaller, cheaper, and easier to manufacture. Operational parameters such as cut-in, cut-out speed, rated wind speed, rated power output, power coefficient, rpm and pitching of blade were analyzed for performing calculations. From wind data it was established that the average wind speed is $5 \mathrm{~m} / \mathrm{s}$ and relative humidity typically varies from the lowest value of $16 \%$ to the highest $85 \%$. From detailed design, it was found that the power density increases as wind velocity increases. All the required design parameters such as the swept area, expected power output, turbine diameter, airfoil type, chord length, number of blades, angular velocity, rated blade velocity, tip speed ratio, lift force, drag force, tangential force, normal force, torque and expected power output were calculated by using the input parameters of the design such as the rotor radius, pitch angle, blade length, blade chord length and number of blades. In the structural analysis of the turbine normal stress, normal force, coefficient of normal force, perpendicular area, shear stress, and bending moment were determined. The maximum voltage the turbine achieved at $6.4 \mathrm{~m} / \mathrm{s}$ wind speed was 2.4 volts and the rotational speed of the turbine was 60.3 RPM. Future development would be to build a mechanism to prevent the wind turbine from rotating at high wind speeds that may damage the blades.

\section{References}

1. P. S. Acosta, S. Tilvaldyev, L. G. G. Anaya, G. E. G. Sánchez and D. A. C. a. J. F. Garay, "ADVANCE HIGH EFFICIENT AERODYNAMIC BLADES FOR VERTICAL AXIS WIND TURBINE MODULAR AGGREGATE," International Journal of Arts \& Sciences, 2012.

2. "Different Types and Parts of a Horizontal Axis Wind Turbines," 17 March 2011. [Online]. Available: https://dolcera.com/wiki/index.php?title=Different Types_and_Parts_of_a_Horizontal_Axis_Wind_Tur bines.

3. M. A. Rosen, J. O. Ajedegba and G. F. Naterer, "Predicting Vertical Axis Wind Turbine Behaviour: Effects of Blade Configuration on Flow Distribution and Power Output," Nova Science Publishers, Inc., Ontario, 2010.

4. M. Ragheb, "Vertical Axis Wind Turbines," University of Illinois at Urbana, Illinois, 2015. 
5. Pac Wind, Sea Hawk Description, California: PacWind INC, 2007.

6. L. S. David A. Rivkin, Wind Energy, Burlington: JONES \& BARTLETT LEARNING, 2013.

7. "UAE looks to tap vast potential of wind power," 14 June 2014. [Online]. Available: http://www.thenational.ae/business/industryinsights/energy/uae-looks-to-tap-vast-potential-ofwind-power.

8. L. Deisadze, D. Digeser, C. Dunn and D. Shoikat, "Vertical Axis Wind Turbine Evaluation and Design," WORCESTER POLYTECHNIC INSTITUTE, Worcester, 2013.

9. Y.-b. Liang, L.-X. Zhang, E.-x. Li, X.-h. Liu and Y. Yang, "Design Considerations of Rotor Configuration for Straight-Bladed Vertical Axis Wind Turbines," Advances in Mechanical Engineering, 2014.

10. "Abu-Dhabi-United-Arab-Emirates," 2016. [Online]. Available: https://weatherspark.com/averages/32854/AbuDhabi-United-Arab-Emirates. [Accessed 28 April 2016].

11. M. Islam, A. Fartaj and R. Carriveau, "Analysis of the Design Parameters related to a Fixed-pitch Straight-Bladed Vertical Axis Wind Turbine," WIND ENGINEERING, 2008.

12. Resource Supply, LLC, "IP67, What Does That Mean?" Tigard, 2008.

13. Y. Zhong-Jia, G. Yi-Zhuo*, L. Min, L. Yan-Xia, L. Jie and a. Z. Zuo-Guang, "Design and Analysis of Small-Scale Lift-Type Vertical-Axis Wind," Key Laboratory of Aerospace Advanced Materials and Performance, Beijing, 2014.

14. J. Castillo, "SMALL-SCALE VERTICAL AXIS WIND TURBINE DESIGN," Tampere University of Applied Sciences, Tampere, 2011. 